\title{
Influence of soil water content and atmospheric conditions on leaf water potential in cv. "Touriga Nacional" deep-rooted vineyards
}

\author{
P. Rodrigues $\cdot$ V. Pedroso $\cdot$ J. P. Gouveia $\cdot$ \\ S. Martins $\cdot$ C. Lopes $\cdot$ I. Alves
}

Received: 29 July 2011/ Accepted: 19 January 2012/Published online: 15 June 2012

(C) Springer-Verlag 2012

\begin{abstract}
In this study, the influence of soil and atmosphere conditions on noon and basal leaf water potential of vines "Touriga Nacional" in the Dão region submitted to different irrigation treatments is analysed. Both indicators showed to be dependent on environmental conditions at the time of measurement. Leaf water potential at noon of fully watered plants was linearly related with atmospheric conditions, with values registered when vapour pressure deficit (VPD) was higher than approximately $3 \mathrm{kPa}$ being no different from the values registered in stressed plants. Therefore, this indicator cannot be reliably used to distinguish different plant water stress levels when atmospheric conditions induce high evaporative demands. The basal leaf water potential $\left(\psi_{\mathrm{b}}\right)$ was also influenced by VPD at the time of measurement for all soil water conditions. In well irrigated plants, it was even possible to establish a baseline that can therefore be used to identify nonwater stressed conditions $\quad\left(\psi_{\mathrm{b}} \quad(\mathrm{MPa})=-0.062-0.0972 \quad\right.$ VPD $\quad(\mathrm{kPa})$, $\left.r^{2}=0.78\right)$. A good correlation was found between soil humidity and $\psi_{\mathrm{b}}$. However, more than the average value of the whole thickness of soil monitored, the $\psi_{\mathrm{b}}$ values were
\end{abstract}

Communicated by V. Sadras.

P. Rodrigues · J. P. Gouveia

Escola Superior Agrária de Viseu, Quinta da Alagoa,

Ranhados, 3500-606 Viseu, Portugal

V. Pedroso - S. Martins

Centro de Estudos Vitivinícolas do Dão,

Quinta da Cale, 3520-090 Nelas, Portugal

C. Lopes - I. Alves $(\square)$

Instituto Superior de Agronomia, Tapada da Ajuda,

1399-017 Lisbon, Portugal

e-mail: isabelmalves@isa.utl.pt dependent on the distribution of soil humidity, with the plants responding to the presence of wet layers.

\section{Introduction}

Due to their deep root system and their physiological mechanisms that control transpiration, vines are well adapted to mediterranean climates (Chaves et al. 2010). However, the combined effect of soil water deficit and high atmospheric evaporative demand that frequently occur during summer time in these regions can be detrimental. Irrigation may therefore be necessary to avoid the plants reaching excessive temperatures, to protect the yield and quality of the grapes and even to guarantee the survival of the vines (Chaves et al. 2010). Suitable indicators of plant water status and thresholds are then needed that can be used for irrigation scheduling. Plant water status is determined by the balance between the water absorption by the roots, that depend on the characteristics of the root system and soil water distribution and availability, and the losses by transpiration, that depend on the atmospheric demand and the stomatal resistance as well as the hydraulic conductivity in the plant. It can be evaluated by several water status indicators. Plant based indicators, like leaf (or stem) water potential, integrate the influence of both the environmental (soil and atmosphere) and plant (internal hydraulic resistances) influences on plant water status and are therefore considered by many authors to be the most reliable.

There are however some different reports in the literature as to which leaf water potential gives the best information about the water status of vines. Williams and Araujo (2002) concluded that basal (predawn) $\left(\psi_{\mathrm{b}}\right)$ and noon $\left(\psi_{\text {noon }}\right)$ leaf water potential and stem water potential 
at noon could be equally viable methods. Carbonneau (1998), Deloire et al. (2005) and Lopes et al. (2011) favour predawn leaf water potential, while Intrigliolo et al. (2005), Salón et al. (2005), Yuste et al. (2004) and Williams and Trout (2005) indicate that minimum leaf water potential is the most useful indicator. Variety and rootstock, soil type and depth, range of soil water deficit, variability of weather conditions throughout the growing cycle, atmospheric evaporative demand, leaf area and fruit load are some of the factors that may explain this discrepancy (Choné et al. 2001; Patakas et al. 2005; Salón et al. 2005; Santesteban et al. 2011; Schmid 1997; Williams and Araujo 2002; Williams and Trout 2005).

It is assumed that leaf water potential equilibrates with soil water potential right before sunrise, and therefore $\psi_{\mathrm{b}}$ is frequently used to assess soil water availability (Choné et al. 2001; Jones and Tardieu 1998; Lopes 1999). The reasoning behind this indicator is that during the night, due to absence of light, necessary to photosynthesis, and given the low needs of cooling of the leaves, stomata are closed and therefore no transpiration losses occur, which allows the re-hydration of the plants and the establishment of an equilibrium between plant and soil water potential. However, there is growing evidence that stomata may not be always closed during the night (Caird et al. 2007), which may lead to a difference between the two water potentials.

Though plant indicators are theoretically more reliable in indicating water status, they are laborious, need to be made at specific times of the day and are difficult to be assessed continuously over long periods. Soil water measurements, on the contrary, may be made at any time of the day and can be automated and the data gathered remotely, which makes them more attractive for the farmer as a tool for irrigation scheduling. Oddly enough, studies that correlate leaf water potential of vines with soil water availability (e.g. Olivo et al. 2008; Paranychianakis et al. 2004; Williams and Trout 2005; Pellegrino et al. 2004) are still scarce. This relationship will also vary with soil type, the evaporative demand of the atmosphere and the hydraulic resistances within the soil-plant system, which will depend on the variety and rootstock, phenological stage and plant age (Schultz and Stoll 2009) and also on soil water distribution within the profile (Améglio and Archer 1996), so relationships may be difficult to apply to other environmental/plant conditions.

Though $\psi_{\text {stem }}$ seems to be a good indicator of water stress in vines (Choné et al. 2001; Patakas et al. 2005), it is laborious and not very attractive to the farmer for irrigation scheduling. The objective of this work was therefore to assess leaf water potential $\left(\psi_{\text {noon }}\right.$ and $\left.\psi_{\mathrm{b}}\right)$ as a water stress indicator of vines of cv. "Touriga Nacional" submitted to different irrigation regimes and the influence of environmental conditions, in particular vapour pressure deficit
(VPD) and soil water availability, on these indicators, aiming at deriving guidelines that may be used in irrigation scheduling.

\section{Materials and methods}

Location and plant material

The field work was carried out at the Centro de Estudos Vitivinícolas do Dão, Nelas, Portugal, in the Dão region (latitude $40^{\circ} 31^{\prime} \mathrm{N}$, longitude $7^{\circ} 51^{\prime} \mathrm{W}$, altitude $440 \mathrm{~m}$ ), with cv. "Touriga Nacional". In 2004 and 2005, the experiment was installed in plot 1-A, and in 2006 and 2007 in plot 5-A. Soils are from granitic origin, therefore having a coarse texture. They have very good infiltration capacity, are low in organic matter content and have a low water retention capacity. The characteristics of the plots, together with information on some physical and soil water properties, are summarized in Table 1. Though at the bottom of the profile monitored some altered original rock was found, total soil depth was not established, being greater than $160 \mathrm{~cm}$. Roots were found at all depths and no limitations to their penetration to lower depths existed.

\section{Experimental design}

A split plot design was used, with four irrigation treatments (no irrigation-NI, full irrigation-FI, and two deficit irrigation treatments-DI30 and DI50) each with three replications.

A drip system was used in the irrigated plots. In plot $1-\mathrm{A}$, the irrigation system consisted in a drip line $(16 \mathrm{~mm}$ diameter) per row of plants, with in-line self-compensating and self-cleaning emitters with a nominal discharge of 2.3 $\mathrm{L} / \mathrm{h}$ spaced $1 \mathrm{~m}$. In plot $5-\mathrm{A}$, the drip line had $1.7 \mathrm{~L} / \mathrm{h}$ emitters, spaced $0.75 \mathrm{~m}$.

The fraction of available soil water (FASW) was calculated as:

FASW $_{0 \rightarrow z}=\frac{\int_{0}^{z}\left(\theta-\theta_{\mathrm{WP}}\right) \mathrm{d} z}{\int_{0}^{z}\left(\theta_{\mathrm{FC}}-\theta_{\mathrm{WP}}\right) \mathrm{d} z}$,

where $\theta$ is measured volumetric water content, $\theta_{\mathrm{FC}}$ is volumetric water content at field capacity $(\sim \mathrm{pF} 2)$, and $\theta_{\mathrm{WP}}$ is volumetric water content at wilting point $(\sim \mathrm{pF} 4.2)$. Irrigation scheduling was based on the fraction of available soil water down to the $60 \mathrm{~cm}$ depth $\left(\mathrm{FASW}_{0 \rightarrow 60}\right)$. In full irrigation plots (FI), where plants were to be maintained without any water stress to achieve $100 \%$ of crop evapotranspiration $\left(\mathrm{ET}_{c}\right)$, irrigation events were scheduled whenever $\mathrm{FASW}_{0 \rightarrow 60}$ reached values around 40-50\%. In the deficit irrigation treatments, DI30 and DI50, the critical levels were 10-20 and 20-30\%, respectively. Irrigation 
depth was calculated from the accumulated values of daily $\mathrm{ET}_{c}$, as determined with the methodology presented by Allen et al. (1998), and rainfall $(P)$ that occurred since the last irrigation event. Full irrigation treatment (FI), therefore, received $100 \%$ of accumulated $\mathrm{ET}_{c}-P$, DI50 received $50 \%$ of $\mathrm{ET}_{c}-P$ and irrigation depths of treatment DI30 corresponded to $30 \%$ of $\mathrm{ET}_{c}-P$.

Measurements and data analysis

Meteorological variables (solar radiation, net radiation, air temperature and humidity, wind speed and rainfall) were measured at a meteorological station installed at the centre of the experimental plot. The sensors were connected to a Campbell Scientific data acquisition system, model CR10X and scanned every minute. Ten minute average values were stored. Hourly, reference evapotranspiration $\left(\mathrm{ET}_{o}\right)$ was determined from the average hourly values of the meteorological variables using the FAO-Penman-Monteith (FAO-PM) equation (Allen et al. 1998), with the values for the surface resistance $\left(r_{c}\right)$ and the coefficients $C_{n}$ and $C_{d}$ proposed by Allen et al. (2006). Daily $\mathrm{ET}_{o}$ values were obtained by integrating the hourly values.

Soil water content was measured with capacitive probes, properly calibrated for the soils of the experiment. Calibration was done by taking three volumetric soil samples adjacent to the access tube at several depths after making the correspondent probe readings. Humidity in the samples was determined by oven drying at $105^{\circ} \mathrm{C}$ until constant weight. Values obtained in very dry $\left(\theta_{V} \approx 5-10 \%\right)$ and wet soil $\left(\theta_{V}>15 \%\right)$ were used. A power function was then fitted between the readings and the volumetric water contents $\left(r^{2}=0.89, \quad \mathrm{RMSE}=0.0218 \mathrm{~m}^{3} / \mathrm{m}^{3}\right)$. Both a fixed, continuous recording system, Enviroscan (Sentek Pty Ltd), with $190 \mathrm{~cm}$ probes with sensors placed every $20 \mathrm{~cm}$, and a portable probe, Diviner 2000 (Sentek Pty Ltd), allowing measurements of soil water content in $10 \mathrm{~cm}$ increments down to a depth of $160 \mathrm{~cm}$, were used. The fixed system was installed in the NI treatment, and the portable probe was used in the irrigated treatments. In each experimental unit, two access tubes were installed, one in the row of plants, between 2 vines and close $(5 \mathrm{~cm})$ to the dripper, and the other at half distance between the rows. In this study, only the information relative to the row is used, as this is the soil region from where vines extracted water preferentially (Rodrigues et al. 2010). Measurements were made at least twice each week, and always before and after irrigations.

Leaf water potential measurements were made with a pressure chamber similar to the one described by Scholander et al. (1965) (PMS Instrument Company, Oregon, USA, model 600) using fully developed, healthy, dry and fully exposed leaves from several plants (seven leaves per 
treatment in 2004 and 2005 and 12 leaves per treatment in 2006 and 2007). Measurements were made between flowering and harvest every 2 weeks, covering all the main phenological stages. In each date, two measurements were made, one before sunrise, corresponding to basal leaf water potential $\left(\psi_{\mathrm{b}}\right)$ and the other around noon $\left(\psi_{\text {noon }}\right)$.

Linear and nonlinear regression analysis was applied to determine the relationships between variables (with $\psi$ being the dependent variable and VPD or FASW the independent variables), using the Statistical Package for the Social Sciences (SPSS for Windows, Standard Version Release 19.01).

\section{Results}

Meteorological conditions during the field experiment

Some meteorological variables measured during the experimental period are presented in Fig. 1. The year 2004 was globally a dry year, but August was very humid, with $106.8 \mathrm{~mm}$ of rainfall, corresponding to 8.4 times the average amount for this month, and with temperatures $2-3{ }^{\circ} \mathrm{C}$ lower than average. The year 2005 was a dry year, with higher than normal temperatures in June and August. The year 2006 was the hottest year, registering the greatest number of days with maximum temperatures close to or higher than $35^{\circ} \mathrm{C}$ and the highest $\mathrm{ET}_{o}$ value $(9.2 \mathrm{~mm} /$ day $)$. The year 2007 was the mildest year, registering temperatures close to the average values, with $\mathrm{ET}_{o}$ values always lower than $8 \mathrm{~mm} /$ day.

Total irrigation amounts and water consumption

Table 2 summarizes the data relative to the irrigation amounts, expressed as irrigation depths $(I)$ and as percentage of the irrigation depth used in treatment FI $\left(I / I_{\max }\right)$, as well as the water consumption by the plants in each treatment (ET) expressed as percentage of the ET
Table 2 Irrigation depths (I), irrigation depths as percentage of the irrigation depth used in treatment FI $\left(I / I_{\max }\right)$, and plant water use as percentage of the plant water use registered in the FI treatment (ET/ $\mathrm{ET}_{\max }$ ) measured between berry set and harvest in the different treatments during the period of the trials

\begin{tabular}{lccc}
\hline Treatment & $\begin{array}{l}I \\
(\mathrm{~mm})\end{array}$ & $\begin{array}{l}I / I_{\max } \\
(\%)\end{array}$ & $\begin{array}{l}\mathrm{ET} / \mathrm{ET}_{\text {max }} \\
(\%)\end{array}$ \\
\hline 2004 & & & \\
NI & 0 & 0.0 & 92.8 \\
DI30 & 58.0 & 27.1 & 89.8 \\
DI50 & 92.0 & 43.0 & 90.3 \\
FI & 213.9 & 100.0 & 100.0 \\
2005 & & & \\
NI & 0 & 0.0 & 65.9 \\
DI30 & 96.6 & 36.0 & 66.7 \\
DI50 & 152.3 & 56.8 & 84.7 \\
FI & 310.5 & 100.0 & 100.0 \\
2006 & & & \\
NI & 0 & 0.0 & 69.2 \\
DI30 & 49.5 & 21.7 & 75.3 \\
DI50 & 99.0 & 43.4 & 89.3 \\
FI & 228.3 & 100.0 & 100.0 \\
2007 & & & 87.9 \\
NI & 0 & 0.0 & 90.4 \\
DI30 & 57.2 & 20.9 & 89.6 \\
DI50 & 101.2 & 37.0 & \\
FI & 273.4 & 100.0 & \\
\hline
\end{tabular}

registered in the $\mathrm{FI}$ treatment $\left(\mathrm{ET} / \mathrm{ET}_{\max }\right)$. Despite the big differences in irrigation depths, differences in plant water use between treatments were less marked. The major differences in water consumption between the several treatments were registered in the dryest (2005) and hottest (2006) years, with deficit and nonirrigated plots showing similar total water consumptions (of about $90 \%$ of FI) in years 2004 and 2007. These results can be explained by the fact that the vine plants have a deep root system that is able to effectively explore the soil water reserves that can
Fig. 1 Monthly precipitation and maximum and average temperatures registered during the experimental periods of 2004-2007

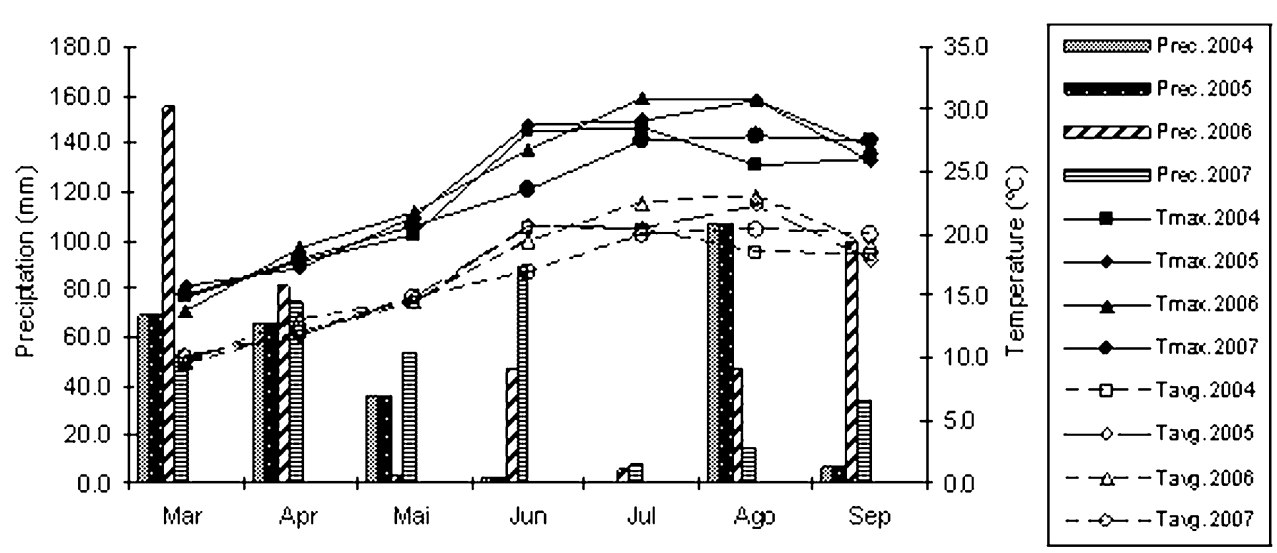


therefore represent a significant fraction of total plant water use (Rodrigues et al. 2010). Thus, irrigation depths cannot, per se, be used to characterize the water regime and/or the water status in vines, and any relations based on irrigation depth alone will lack real meaning. Also, the similarity in total water use indicates that plant water stress was not so different between treatments nor did it attain the levels that could be expected beforehand, namely in the nonirrigated plots.

Leaf water potential at noon $\left(\psi_{\text {noon }}\right)$

Two distinct soil water conditions were considered: available soil water in the soil layer with $160 \mathrm{~cm}$ depth greater than $40 \%$ of total available water $\left(\mathrm{FASW}_{0 \rightarrow 160}>40 \%\right)$ (corresponding to full soil water availability conditions) and $\mathrm{FASW}_{0 \rightarrow 160}<20 \%$ (severe soil water stress conditions). The relationship between $\psi_{\text {noon }}$ values and VPD at the time of the measurement is shown in Fig. 2.

In well-watered plants $\left(\mathrm{FASW}_{0 \rightarrow 160}>40 \%\right)$, the differences in the value of $\psi_{\text {noon }}$ can be explained by the differences in atmospheric conditions at the time of measurement, as indicated by the high determination coefficients $\left(r^{2}=0.68\right)$. The values of $\psi_{\text {noon }}$ are inversely correlated to VPD, reaching values as low as -1.4 to $-1.6 \mathrm{MPa}$. In soil water stressed conditions (FASW F $_{0 \rightarrow 160}<20 \%$ ), the values of $\psi_{\text {noon }}$ have low dependency on air VPD at the time of measurement. Values obtained on both soil water conditions can reach similar values for high evaporative conditions $(\mathrm{VPD}>3 \mathrm{kPa})$.

\section{Basal leaf water potential $\left(\psi_{\mathrm{b}}\right)$}

Values of basal leaf water potential $\left(\psi_{\mathrm{b}}\right)$ were generally maintained above $-0.2 \mathrm{MPa}$ in the FI treatment, indicating the absence of water stress (Carbonneau 2001; Zufferey 2000). Therefore, the irrigation scheduling and the irrigation amounts used in the FI treatment were adequate to keep these plants well watered, allowing maximum crop evapotranspiration. These plants thus also set an upper limit, corresponding to full water availability, to which the values obtained in the other irrigation treatments can be compared.

Data were divided in three groups according to soil water reserve. In all groups, basal leaf water potential showed to be dependent on the atmospheric conditions at the time of measurement (Figs. 3, 4, 5), as indicated by the high determination coefficients $\left(r^{2}\right)$ obtained with the regression analysis performed between the values of $\psi_{\mathrm{b}}$ and VPD.

From Fig. 3, it can be seen that the relationship between $\psi_{\mathrm{b}}$ and VPD in well-watered plants $\left(\mathrm{FASW}_{0 \rightarrow 160}>40 \%\right.$ ) is similar in all 4 years of experiment. In plants submitted
Fig. 2 Relationship between leaf water potential at noon $\left(\psi_{\text {noon }}\right)$ measured in plants submitted to two different soil

FASW $_{0 \rightarrow 160}>40 \%$ and water conditions FASW $_{0 \rightarrow 160}<20 \%$ ) and VPD

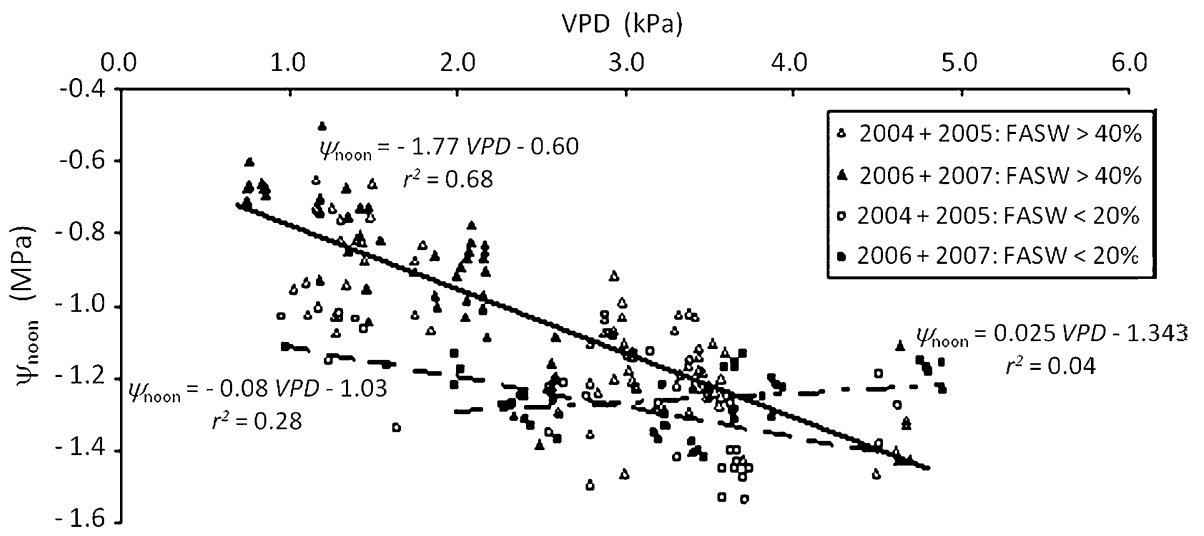

Fig. 3 Relationship between basal leaf water potential $\left(\psi_{\mathrm{b}}\right)$ when FASW $_{0 \rightarrow 160}>40 \%$ and VPD. Full line represents the regression line determined with the data from plot 1-A (2004 and 2005) and plot 5-A (2006 and 2007)

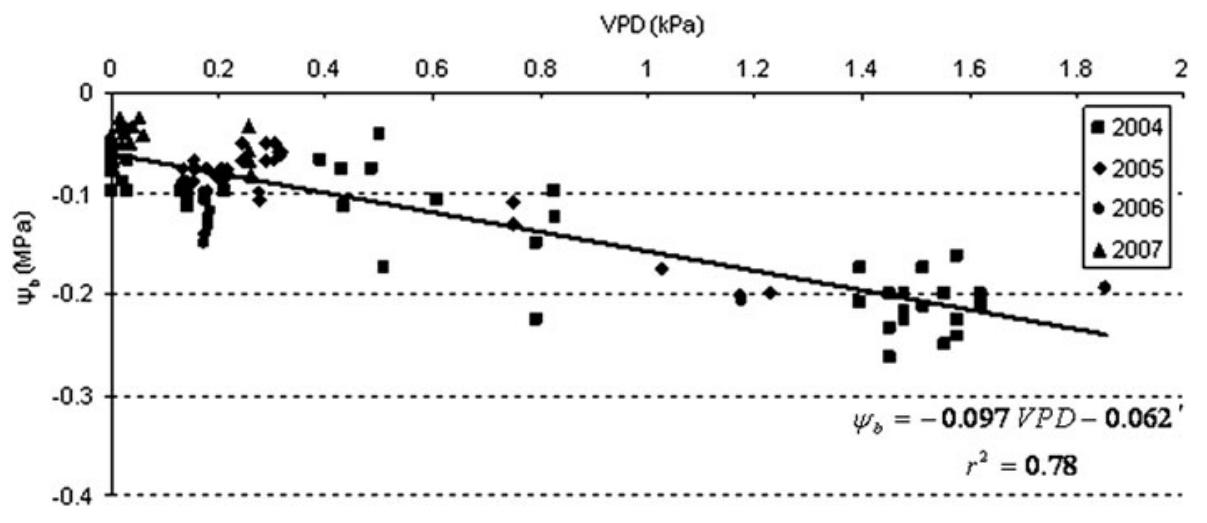


Fig. 4 Relationship between basal leaf water potential $\left(\psi_{\mathrm{b}}\right)$ when $\mathrm{FASW}_{0 \rightarrow 160}<20 \%$ and VPD. Full line represents the regression line determined with the data from plot 1-A (2004) and from plot 5-A (2006 and 2007), the dashed line represents the regression line determined with the data from plot 1-A (2005)

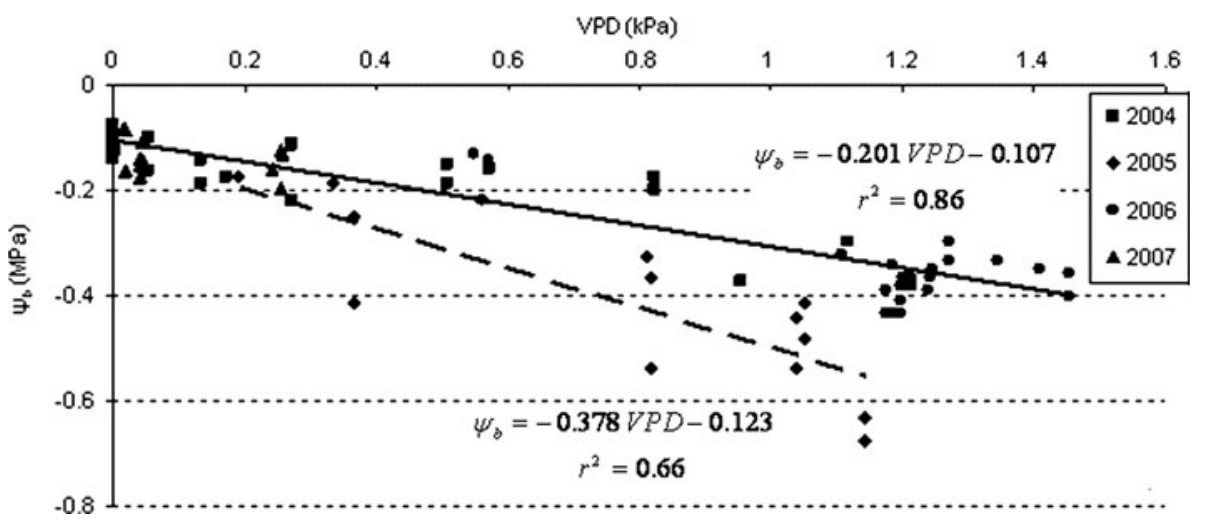

Fig. 5 Relationship between basal leaf water potential $\left(\psi_{\mathrm{b}}\right)$ when $20 \%<$ FASW $_{0 \rightarrow 160}$ $<40 \%$ and VPD. Full line represents the regression line determined with the data from plot 1-A (2004 and 2005) and from plot 5-A (2006 and 2007)

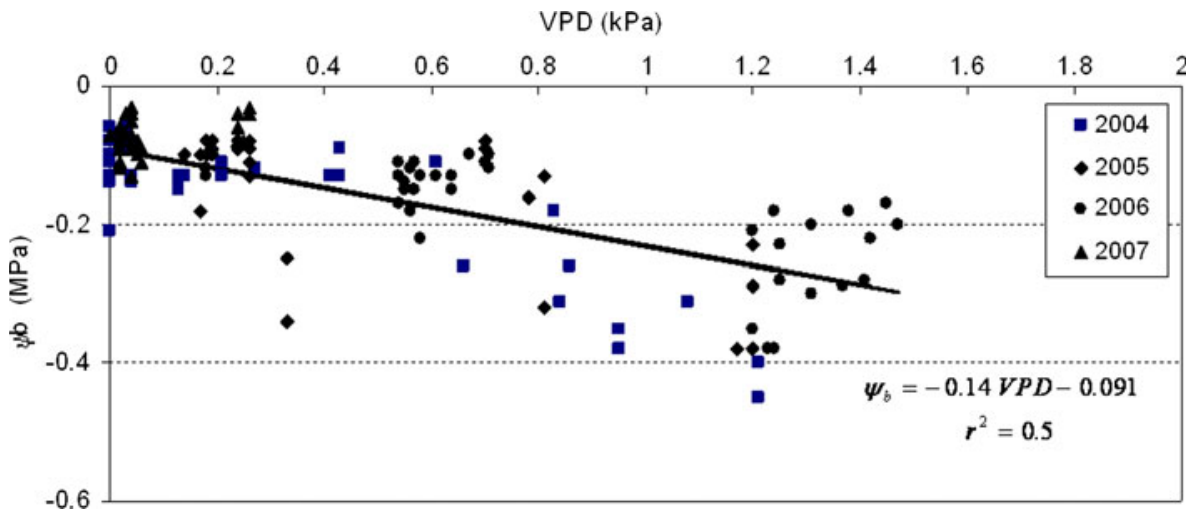

to low soil water availability conditions $\left(\mathrm{FASW}_{0 \rightarrow 160}\right.$ $<20 \%$ ), basal leaf water potential is also dependent on atmospheric conditions at the time of measurement (Fig. 4). However, it is not possible to establish a single relationship, as the line corresponding to 2005, the driest year, that led to the lowest values of $\psi_{\mathrm{b}}$ observed, has a steeper slope than the one that can be derived from the data gathered in the other years. The intermediate soil water conditions $\left(20 \%<\mathrm{FASW}_{0 \rightarrow 160}<40 \%\right)$ led to intermediate $\psi_{\mathrm{b}}$ values that showed a lower relationship $\left(r^{2}=0.50\right)$ with VPD (Fig. 5).

Values of $\psi_{\mathrm{b}}$ higher than $-0.2 \mathrm{MPa}$ (indicative of nonwater stressed conditions) were registered when VPD values were lower than $0.3 \mathrm{kPa}$, even with very low soil water reserves.

Influence of soil water availability and soil water profile on the basal leaf water potential

Due to limitations of the measurement method, the soil properties and/or the root system of the crops (as is the case of vines, that have very deep root systems), it may not be always possible to monitor FASW in the entire root zone. In such a case, it is thus important to first determine the minimum depth that must be monitored in order to obtain a reliable indicator of plant water status.
Therefore, the determination coefficients $\left(r^{2}\right)$ of the adjustment of the function of the type $\psi_{\mathrm{b}}=a / \mathrm{FASW}$, using different soil depths, were assessed. The results are presented in Fig. 6.

In treatment FI, determination coefficients are always very high, which means that even considering a small soil depth FASW can be a reliable indicator of plant water status $\left(\psi_{\mathrm{b}}\right)$. This is due to the fact that vines extract water preferably from soil layers high in humidity (Rodrigues et al. 2010) that, in the case of the fully irrigated plot, correspond to the upper soil layer. On the contrary, in deficit irrigated plots (DI30 and DI50) and in the nonirrigated plot (NI), vines extract water from deeper layers, and therefore in these plots a thicker layer of soil must be monitored to get a value that can reliably be related to plant water status. In this experiment, the highest $r^{2}$ values were obtained when a soil depth equal or greater than $130 \mathrm{~cm}$ is considered, so subsequently the fraction of available soil water calculated for a $130 \mathrm{~cm}$ soil thickness $\left(\mathrm{FASW}_{0 \rightarrow 130}\right)$ was used.

Figure 7 presents the relationship between $\psi_{\mathrm{b}}$ and FASW $_{0 \rightarrow 130}$ using the values measured in all treatments during the whole trial. Two regions can be identified, corresponding to different atmospheric evaporative demands (VPD) at the time of measurement. High values of leaf water potential $(>-0.2 \mathrm{MPa})$ can be obtained with a vast 
Fig. 6 Determination coefficients of the adjusted function between the values of $\psi_{\mathrm{b}}$ and the correspondent values of FASW considering an increasing soil depth for the four irrigation treatments in plot 1-A (2004 and 2005)

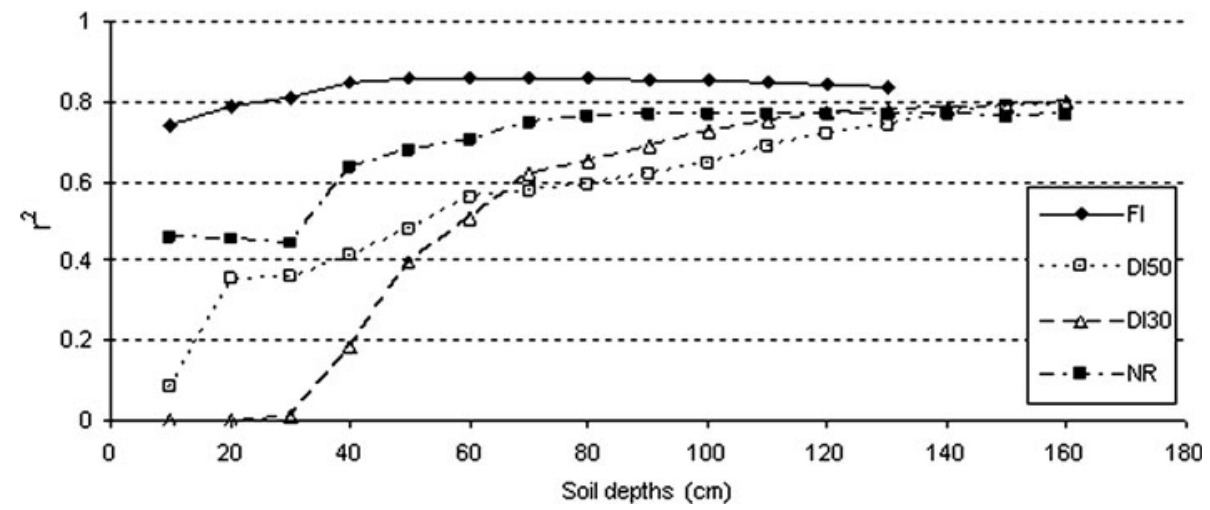

Fig. 7 Relationship between $\psi_{\mathrm{b}}$ and $\mathrm{FASW}_{0 \rightarrow 130}$ considering all the values obtained in all treatments. Both curves have the general equation $\psi_{\mathrm{b}}=a /$ FASW $_{0 \rightarrow 130}+b$ (for $\mathrm{VPD}<1 \mathrm{kPa}: a=-1.916$, $b=-0.048$; for VPD $>1 \mathrm{kPa}$ : $a=-1.873, b=-0.206$ )

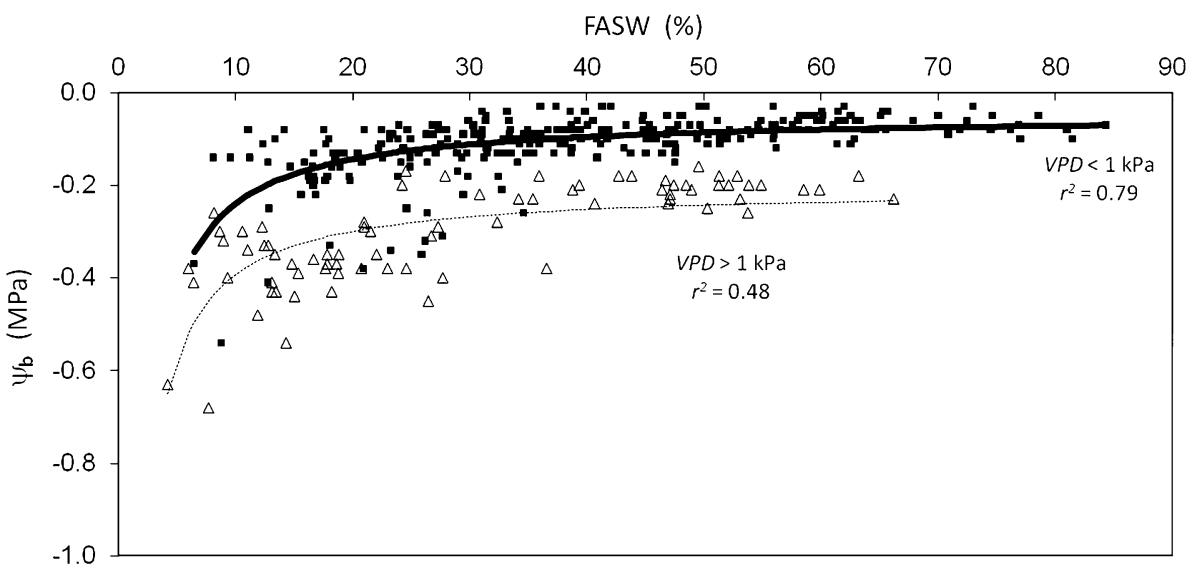

Table 3 Basal leaf water potential, fraction of available soil water down to $160 \mathrm{~cm}$ deep $\left(\mathrm{FASW}_{0 \rightarrow 160}\right)$, air temperature $\left(T_{\mathrm{a}}\right)$, relative humidity $(\mathrm{RH})$ and vapour pressure deficit (VPD) recorded in DOY 247 and 249 of 2006, in plot 5-A, in treatments FI and DI30

\begin{tabular}{|c|c|c|c|c|c|c|c|}
\hline \multirow[t]{2}{*}{ DOY } & \multicolumn{2}{|l|}{$\psi_{\mathrm{b}}(\mathrm{MPa})$} & \multicolumn{2}{|l|}{$\mathrm{FASW}_{160}$} & \multirow[t]{2}{*}{$T_{\mathrm{a}}\left({ }^{\circ} \mathrm{C}\right)$} & \multirow[t]{2}{*}{$\mathrm{RH}(\%)$} & \multirow[t]{2}{*}{$\mathrm{VPD}(\mathrm{kPa})$} \\
\hline & FI & DI30 & FI & DI30 & & & \\
\hline 247 & $-0.19 \pm 0.08$ & $-0.37 \pm 0.06$ & $48.3 \pm 6.3$ & $13.9 \pm 4.1$ & $20.2 \pm 0.7$ & $39.9 \pm 2.2$ & $1.43 \pm 0.11$ \\
\hline 249 & $-0.18 \pm 0.05$ & $-0.19 \pm 0.05$ & $39.0 \pm 6.0$ & $28.8 \pm 5.2$ & $21.3 \pm 0.2$ & $43.9 \pm 0.8$ & $1.42 \pm 0.04$ \\
\hline
\end{tabular}

range of soil humidity conditions, provided the VPD is low, as could be already seen previously (Figs. 3, 4, 5); for the same values of FASW, lower values of $\psi_{\mathrm{b}}$ are recorded when air is drier.

Though there is a relationship between $\psi_{\mathrm{b}}$ and FASW $_{0 \rightarrow 130}$, it is not a perfect one, as similar $\psi_{\mathrm{b}}$ are recorded in different FASW values and, conversely, different $\psi_{\mathrm{b}}$ occur for similar FASW values. This is due to the fact that FASW $\mathrm{F}_{0 \rightarrow 130}$ is an integrated, average value for the monitored layer that gives no indication on the variability of the water content within the soil profile.

In Table 3 and Fig. 8, the values collected on DOY 247 and 249 of year 2006, before and after the 3rd irrigation event in treatment DI30 and 1 and 3 days after the 7 th irrigation event in FI treatment, are presented. Atmospheric conditions were similar for the two periods. As to treatment
FI, and though there was a reduction in FASW $_{0 \rightarrow 160}$ between DOY 247 and 249, the FASW in the upper layer was maintained above $40 \%$ (full water availability), and $\psi_{\mathrm{b}}$ was also maintained high, showing no stress. In treatment DI30, soil water storage was low before irrigation, and therefore the measured value of $\psi_{\mathrm{b}}$ was also low. After the irrigation event, FASW $\mathrm{F}_{0 \rightarrow 160}$ increased, though attaining lower values than those that were registered in treatment FI, yet the values of basal leaf water potential were similar in the two treatments. Analysing the soil humidity profile, it can be seen that though FASW $_{0 \rightarrow 160}$ had a relatively small increase, the irrigation event caused a significant increase of humidity in the upper soil layer, that reached FASW values greater than $40 \%$.

In order to evaluate the influence of the distribution of water within the soil profile on the values of basal leaf 
Fig. 8 Profile of FASW in DOY 247 and 249 of 2006 in treatments a FI and b DI30. The markers represent the average values (four repetitions) of each layer, and the bars correspond to the standard error
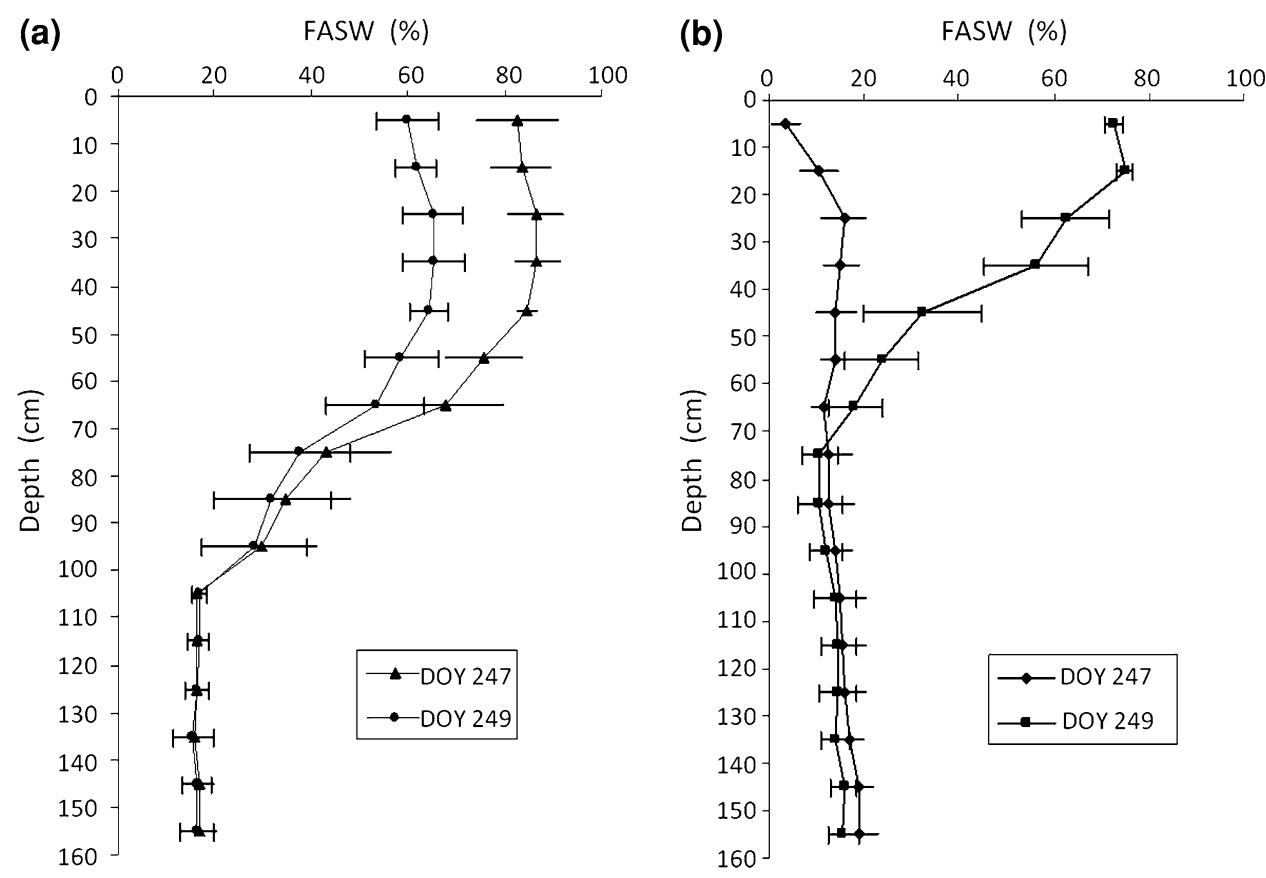

water potential, the average percentage of soil thicknesses with FASW values lower than $10 \%$, between 10 and $20 \%$, between 20 and $30 \%$, between 30 and $40 \%$ and greater than $40 \%$, corresponding to conditions of progressively more humid soil, were determined for each class of $\psi_{\mathrm{b}}$ values (Table 4). Layers considered were 0-20, 20-40, $40-70,70-100,100-130$ and $130-160 \mathrm{~cm}$. The analysis of the results show that $\psi_{\mathrm{b}}$ decreases as the proportion of very dry soil (FASW $<10 \%$ ) increases and, inversely, that the values of $\psi_{\mathrm{b}}$ increase as the proportion of wet soil (FASW $>40 \%)$ increases. The higher values $\left(\psi_{\mathrm{b}} \geq-0.1 \mathrm{MPa}\right)$ were obtained when in approximately two-third $(66 \%)$ of the depth-monitored FASW was greater than $40 \%$, even if soil humidity in other layers was lower. On its turn, $\psi_{\mathrm{b}}$ values lower than $-0.4 \mathrm{MPa}$ were obtained when in all layers of the whole soil profile FASW was less than $40 \%$, and values lower than $-0.5 \mathrm{MPa}$ occurred when all the layers in the whole profile had a FASW lower than $30 \%$. The lowest values $\left(\psi_{\mathrm{b}}<-0.6 \mathrm{MPa}\right)$ were recorded when practically the whole soil profile $(87.5 \%)$ was close to the wilting point (FASW $<10 \%)$.

\section{Discussion}

Leaf water potential at noon $\left(\psi_{\text {noon }}\right)$

Though Williams (2001) considers that $\psi_{\text {noon }}$ should not fall below -1.0 MPa to ensure that vines are well irrigated, in this trial, lower values were obtained even in well-irrigated plots when VPD exceeded $2 \mathrm{kPa}$. Any reference values must therefore be regarded cautiously before adopting them in different, more extreme, climatic conditions.

Very good correlation coefficients between the values of $\psi_{\text {noon }}$ and VPD were obtained in well-watered plants $\left(\right.$ FASW $_{0 \rightarrow 160}>40 \%$ ), but not in plants submitted to low soil water availabilities (FASW F $\rightarrow 160_{20} \%$ ). Similar

Table 4 Average percentage of soil thickness with the different classes of values of FASW and the corresponding classes of values of basal leaf water potential $\left(\psi_{\mathrm{b}}\right)$

\begin{tabular}{|c|c|c|c|c|c|c|c|}
\hline \multirow[t]{2}{*}{ FASW (\%) } & \multicolumn{7}{|l|}{$\psi_{\mathrm{b}}(\mathrm{MPa})$} \\
\hline & {$[-0.7 ;-0.6]$} & {$[-0.6 ;-0.5]$} & {$[-0.5 ;-0.4]$} & {$[-0.4 ;-0.3]$} & {$[-0.3 ;-0.2]$} & {$[-0.2 ;-0.1]$} & $\geq-0.1$ \\
\hline$<10$ & 87.5 & 50.0 & 33.1 & 19.8 & 10.9 & 7.5 & 2.1 \\
\hline$[10 ; 20]$ & 6.3 & 43.8 & 48.1 & 36.3 & 22.9 & 17.1 & 7.6 \\
\hline$[20 ; 30]$ & 6.3 & 6.3 & 13.8 & 29.8 & 18.6 & 22.0 & 11.5 \\
\hline$[30 ; 40]$ & 0.0 & 0.0 & 5.0 & 9.7 & 11.1 & 19.0 & 12.5 \\
\hline$\geq 40$ & 0.0 & 0.0 & 0.0 & 4.4 & 36.5 & 34.4 & 66.3 \\
\hline
\end{tabular}


results were observed by Williams and Baeza (2007) that, from measurements in four varieties in several locations, $75 \%$ of the variation in the values of $\psi_{\min }$ in plants with full water availability was explained by the values of VPD at the time of measurement, and that in nonirrigated plants or in deficit irrigation treatments this indicator was less sensitive to the meteorological conditions. Rogiers et al. (2009) also obtained a strong linear correlation $\left(r^{2}=0.83\right)$ between $\psi_{\text {min }}$ and VPD in well watered plants of cv. "Semillon". In these conditions, they verified that values of $\psi_{\text {min }}$ lower than $-1.0 \mathrm{MPa}$ were registered only when $\mathrm{VPD}>3 \mathrm{kPa}$.

These results are not unexpected. When plants can easily extract water from the soil, high evaporative demands (high VPD) induce high transpiration rates that lead to a transient fall in leaf water content and thus in leaf water potential. When, on the contrary, soil water reserves are low, plants close their stomata to hinder water losses, avoiding a fall in water potential that would not be recoverable (Naor and Wample 1994; Schultz and Matthews 1988). Therefore, values from high-transpiring plants tend to become similar to the ones registered in stressed plants.

Thus, from the results obtained in this experiment, no differences in leaf water potential at noon between plants in different water stress conditions are to be expected whenever VPD is higher than $3 \mathrm{kPa}$ (Fig. 2). Therefore, this variety behaved as isohydric in this experiment, though Chaves et al. (2010) and Lovisolo et al. (2010) describe the behaviour of cv. "Touriga Nacional" as anisohydric. Responses to water deficits in a specific variety are influenced by rootstock, climate (namely VPD and temperature) and intensity and duration of water deficits (Chaves et al. 2010), so the classification of a variety as iso- or anisohydric should not be considered strictly but rather dependent on the particular set of conditions. Since two vineyards were used, with different ages, rootstocks and plant spacing, and different soil water regimes occurred in the different years, the behaviour of the "Touriga Nacional" variety in this experiment seems to have been mainly determined by the climatic conditions (high VPD).

Given the isohydric behaviour verified in this experiment, it can then be concluded that leaf water potential at noon cannot be considered a good indicator of water stress in this variety and these conditions and consequently is not useful for irrigation scheduling in this region and possibly in similar climatic conditions characterized by high atmospheric evaporative demands.

\section{Basal leaf water potential $\left(\psi_{\mathrm{b}}\right)$}

As was observed with the leaf water potential at noon, also basal leaf water potential showed to be dependent on the atmospheric conditions at the time of measurement
(Figs. 3, 4, 5), as indicated by the high determination coefficients $\left(r^{2}\right)$ obtained with the regression analysis performed between the values of $\psi_{\mathrm{b}}$ and VPD, in all soil water conditions. These results (different values of $\psi_{\mathrm{b}}$ in response to VPD values, despite the same soil water conditions) suggest that transpiration occurs even during the night period. The negative correlation between $\psi_{\mathrm{b}}$ and VPD indicates that as evaporative demand of the atmosphere increases, the same happens to the rate of transpiration during the night, which hinders the night-time plant rehydration, that may then not be completed by the end of the night (Rogiers et al. 2009), causing a difference between leaf and soil water potential (Donovan et al. 2001; Bucci et al. 2004; Kavanagh et al. 2007). Schmid (1997) showed that sap flow rate in vines was directly proportional to VPD during the night, which is another indication that the stomata may not close completely during the night. Nighttime transpiration has been reported in other species (Oren et al. 2001; Bucci et al. 2004; Caird et al. 2007) and can represent as much as 5-15\% of daily transpiration (Caird et al. 2007; Rogiers et al. 2009). The reduction in stem conductivity and the transfer of water from humid regions of the soil to the roots and soil in drier regions ("hydraulic lift") can be other possible causes for the "predawn disequilibrium" (Lovisolo et al. 2010; Smart et al. 2005; Bucci et al. 2004).

A single linear relationship between $\psi_{\mathrm{b}}$ and VPD was found that can be used as a reference upper baseline corresponding to full water availability for irrigation scheduling of this variety in this region. However, the use of such a baseline requires that meteorological variables be measured at the same time as leaf water potential, making the use of this indicator less attractive for practical use. Moreover, in vines, the objective of irrigation scheduling is not to completely avoid water stress, which promotes an excessive vegetative growth and is detrimental in terms of wine quality (Gouveia et al. 2011).

Values of $\psi_{\mathrm{b}}$ higher than $-0.2 \mathrm{MPa}$ (indicative of nonwater stressed conditions) were registered in all soil water availability conditions when VPD values were lower than $0.3 \mathrm{kPa}$. These conditions are favourable to the formation of dew that may on itself cause leaf rehydration and thus a higher $\psi_{\mathrm{b}}$ (Limm et al. 2009; Munne-Bosch et al. 1999). High air humidity also leads to a low evaporative demand and, consequently, low or null night-time transpiration rates that allow the equilibrium between the soil and the plant water potential to be achieved more easily, even in severe soil water stress conditions. As the top layer was practically dry, it can be concluded that the root system was in contact with wet soil under the depth monitored $(160 \mathrm{~cm})$ from where it was able to extract water. This conclusion is supported by the values of daily transpiration observed in treatment NI in this period being higher than 
the measured variation of storage in the monitored soil layer (data not published yet). However, this deep extraction could not maintain transpiration at maximum rate throughout the day, and so these high $\psi_{\mathrm{b}}$ values did not represent a true stress free condition. Santesteban et al. (2011) also alert for the fact that similar $\psi_{\mathrm{b}}$ values may not correspond to the same degree of water deficit. Therefore, the interpretation of basal leaf water potentials is not straightforward and can only be reliably made, specially in vineyards installed in deep soils such as the ones of this experiment, where the roots may have access to water beyond the monitored upper soil layer, if concurrent soil and atmosphere information are gathered.

Relationship between $\psi_{\mathrm{b}}$ and VPD was much weaker for intermediate soil water conditions $(20 \%<$ FASW $<$ $40 \%$ ). Also, though a relationship between $\psi_{\mathrm{b}}$ and FASW was found, there was a certain dispersion around the curve (different $\psi_{\mathrm{b}}$ values for the same FASW) and, given the shape of the adjusted curve, similar values of $\psi_{\mathrm{b}}$ may correspond to different values of FASW. This is due to the fact that $\mathrm{FASW}_{0 \rightarrow 130}$ is an integrated, average value for the monitored layer that gives no indication on the variability of the water content within the soil profile, specially for the intermediate values of soil water content. However, vines tend to equilibrate with the wetter layers in the root zone (Améglio and Archer 1996; Pellegrino et al. 2004). Table 4 shows the effect that the presence of wet layers in the soil profile has on plant water potential, since $\psi_{\mathrm{b}}$ decreases as the proportion of very dry soil (FASW $<10 \%$ ) increases and, inversely, the values of $\psi_{\mathrm{b}}$ increase as the proportion of wet soil (FASW $>40 \%$ ) increases.

Therefore, though there is a relation between soil water content and basal leaf water potential, the presence of wet layers determine the final response of the plants more than the average soil moisture content does, which makes the use of soil water measurement for irrigation scheduling somewhat complicated if the objective is to submit the crop to a predetermined water stress level, as may be required for wine making.

\section{Conclusions}

In this work, both leaf water potential at noon and basal leaf water potential were analysed as plant water status indicators as influenced by atmospheric and soil conditions, as well as their possible use for irrigation scheduling.

Both indicators showed to be dependent not only on soil water status but also on the atmospheric conditions at the time of measurement.

The leaf water potential at noon $\left(\psi_{\text {noon }}\right)$ of fully watered plants $\left(\mathrm{FASW}_{0 \rightarrow 160}>40 \%\right)$ was linearly correlated to air humidity, with values registered when VPD was higher than approximately $3 \mathrm{kPa}$ being similar to the values registered in stressed plants $\left(\mathrm{FASW}_{0 \rightarrow 160}<20 \%\right.$ ). Therefore, the "Touriga Nacional" variety behaved as isohydric in this experiment and this indicator cannot be reliably used to distinguish different plant water stress levels when atmospheric conditions induce high evaporative demands.

The basal leaf water potential $\left(\psi_{\mathrm{b}}\right)$ also demonstrated to be dependent on VPD for all soil water conditions. In wellirrigated plants, it was even possible to establish a baseline that can therefore be used to identify nonwater stressed conditions. This shows however that $\psi_{\mathrm{b}}$ values are not useful per se as is normally considered but must be combined with simultaneous measurements of air humidity, which complicates the method and makes it less attractive for practical use.

A good correlation was found between soil humidity and $\psi_{\mathrm{b}}$. However, more than the average value of the whole thickness of soil monitored, the $\psi_{\mathrm{b}}$ values were dependent on the distribution of soil humidity, with the plants responding to the presence of wet layers in the soil profile. Generally, $\psi_{\mathrm{b}}$ decreased as the proportion of very dry soil (FASW $<10 \%$ ) increased and the proportion of wet soil decreased, with nonstressed conditions being achieved when two-third of the profile had humidity levels within the readily available water (FASW $>40 \%$ ).

Acknowledgments This work was financed by the Fundação para a Ciência e a Tecnologia (FCT) through the Project POCTI/AGG/ 38506/2001 "A rega da vinha—sua influência no rendimento e na qualidade da casta Touriga Nacional na Região do Dão”.

\section{References}

Allen RG, Pereira LS, Raes D, Smith M (1998) Crop evapotranspiration. Guidelines for computing crop water requirements. FAO Irrigation and Drainage Paper 56, FAO, Rome

Allen RG, Pruitt WO, Wright JL, Howell TA, Francesca V, Snyder R, Itenfisu D, Steduto P, Berengena J, Yrisarry JB, Smith M, Pereira LS, Raes D, Perrier A, Alves I, Walker I, Elliot R (2006) A recommendation on standardized surface resistance for hourly calculation of reference ETo by the FAO56 Penman-Monteith method. Agric Water Manage 81:1-22

Améglio T, Archer P (1996) Représentativité du potentiel de base sur sols à humidité hétérogène. Agronomie 16:493-503

Bucci SJ, Scholz FG, Goldstein G, Meinser FC, Hinojosa JA, Hoffmann WA, Franco AC (2004) Processes preventing nocturnal equilibration between leaf and soil water potential in tropical savanna woody species. Tree Physiol 24:1119-1127

Caird MA, Richards JH, Donovan LA (2007) Night time stomatal conductance and transpiration in $\mathrm{C}_{3}$ and $\mathrm{C}_{4}$ plants. Plant Physiol 143:4-10

Carbonneau A (1998) Aspects qualitatifs. Irrigation, vignoble et produits de la vigne. In: Tiercelin JR (ed) Traité d'irrigation. Tec\&Doc. Lavoisier Ed, Paris, pp 257-276

Carbonneau A (2001) Water management in the vineyard. Theory and practice. In: 12èmes Journées GESCO. Journée professionnelle: "Gestion de 1'eau dans le vignoble", AGRO Montpellier, Montpellier, pp 3-21 
Chaves MM, Zarrouk O, Francisco R, Costa JM, Santos T, Regalado AP, Rodrigues ML, Lopes CM (2010) Grapevine under deficit irrigation: hints from physiological and molecular data. Ann Bot 105:661-676

Choné X, Van Leeuwen C, Dubourdieu D, Gaudilléres JP (2001) Stem water potential is a sensitive indicator of grapevine water status. Ann Bot 87:477-483

Deloire A, Ojeda H, Zebic O, Bernard N, Hunter J-J, Carbonneau A (2005) Influence de l'état hydrique de la vigne sur le style de vin. Le Progrès Agricole et Viticole 122(21):455-462

Donovan LA, Linton MJ, Richards JH (2001) Predawn plant water potential does not necessarily equilibrate with water potential under well-watered conditions. Oecologia 129:328-335

Gouveia JP, Pedroso V, Rodrigues P, Martins S, Alves I, Lopes C (2011) Effects of irrigation on the vigour, yield and berry composition of the red variety Touriga Nacional at the Dão winegrowing region of Portugal. In: 17th international symposium GiESCO 2011, Asti-Alba (CN), Italy, 29 August-2 September 2011 (in press)

Intrigliolo DS, Castell JR, Perez D (2005) Water relations of field grown drip irrigated Tempranillo grapevines. Acta Hortic 684:317-323

Jones HG, Tardieu F (1998) Modelling water relations of horticultural crops: a review. Sci Hortic 74:21-46

Kavanagh KL, Pangle R, Schotzko AD (2007) Nocturnal transpiration causing disequilibrium between soil and stem predawn water potential in mixed conifer forest of Idaho. Tree Physiol 27:621-629

Limm EB, Simonin KA, Bothman AG, Dawson TE (2009) Foliar water uptake: a common water acquisition strategy for plants of the redwood forest. Oecologia 161:449-459

Lopes C (1999) Relationships between leaf water potential and photosynthetic activity of field-grown grapevines under a Mediterranean environment. In: Rühl EH, Schmid J (eds) Proceedings of the first ISHS workshop on water relations of grapevines, Acta Hortic 493:287-289

Lopes CM, Santos TP, Monteiro A, Rodrigues ML, Costa JM, Chaves MM (2011) Combining cover cropping with deficit irrigation in a Mediterranean low vigor vineyard. Sci Hortic 129:603-612

Lovisolo C, Perrone I, Carra A, Ferrandino A, Flexas J, Medrano H, Schubert A (2010) Drought-induced changes in development and function of grapevines (Vitis spp.) organs and in their hydraulic and non-hydraulic interactions at the whole-plant level: a physiological and molecular update. Funct Plant Biol 37:98-116

Munne-Bosch S, Nogues S, Alegre L (1999) Diurnal variations of photosynthesis and dew absorption by leaves in two evergreen shrubs growing in Mediterranean field conditions. New Phytol 144:109-119

Naor A, Wample RL (1994) Gas exchange and water relations of field grown concord (Vitis labruscana Bailey) grapevines. Am J Enol Vitic 45:333-337

Olivo N, Girona J, Marsal J (2008) Seasonal sensitivity of stem water potential to vapour pressure deficit in grapevine. Irrig Sci 27(2):175-182

Oren R, Sperry JS, Ewers BE, Pataki DE, Phillips N, Megonigal JP (2001) Sensitivity of mean canopy stomatal conductance to vapour pressure deficit in a flooded Taxodium distichum $\mathrm{L}$. forest: hydraulic and non-hydraulic effects. Oecologia 126: $21-29$
Paranychianakis NV, Chartzoulakis KS, Angelakis AN (2004) Influence of rootstock, irrigation level and recycled water on water relations and leaf gas exchange of Soultanina grapevines. Environ Exp Bot 52:185-198

Patakas A, Noitsakis B, Chouzouri A (2005) Optimization of irrigation water use in grapevines using the relationship between transpiration and plant water status. Agric Ecosyst Environ 106:253-259

Pellegrino A, Lebon E, Voltz M, Wery J (2004) Relationships between plant and soil water status in vine (Vitis vinifera L.). Plant Soil 266:129-142

Rodrigues P, Gouveia JP, Pedroso V, Martins S, Lopes C, Alves I (2010) Padrão de extracção de água do solo numa vinha da casta Touriga Nacional no "terroir" do Dão. Poster paper 14, X Simposium Hispano-Português de Relaciones Hídricas en las Plantas. Herramientas para un uso eficiente del agua (Cartagena, 6-8 Octubre 2010), pp 235-238

Rogiers SY, Greer DH, Hutton RJ, Landsberg JJ (2009) Does nighttime transpiration contribute to anisohydric behaviour in a Vitis vinifera cultivar? J Exp Bot 60:3751-3763

Salón JL, Chirivella C, Castel JR (2005) Response of cv. Bobal to timing of deficit irrigation in Requena, Spain: water relations, yield, and wine quality. Am J Enol Vitic 56:1-8

Santesteban LG, Miranda C, Royo JB (2011) Suitability of pre-dawn and stem water potential as indicators of vineyard water status in cv. Tempranillo. Aust J Grape Wine Res 17:43-51

Schmid J (1997) Xylemflussmessungen an Reben. Geisenheimer Berichte, Band 33

Scholander PF, Hammel HT, Bradstreet ED, Hemmingen AE (1965) Sap pressure in vascular plants. Science 148:339-346

Schultz HR, Matthews MA (1988) Resistance to water transport in shoots of Vitis vinifera L. Plant Physiol 88:718-724

Schultz HR, Stoll M (2009) Critical issues in grapevine environmental physiology. Aust J Grape Wine Res 16:4-24

Smart DR, Carlisle E, Goebel M, Núňez BA (2005) Transverse hydraulic redistribution by a grapevine. Plant Cell Environ 28:157-166

Williams LE (2001) Irrigation of wine grapes in California. Practical Winery Vineyard Journal (Nov-Dec):42-55

Williams LE, Araujo FJ (2002) Correlation among predawn leaf, midday leaf, and midday stem water potential and their correlations with other measures of soil and plant water status in Vitis vinifera. J Am Soc Hortic Sci 127(3):448-454

Williams LE, Baeza P (2007) Relationships among ambient temperature and vapour pressure deficit and leaf and stem water potentials of fully irrigated, field-grown grapevines. Am J Enol Vitic 58(2):173-181

Williams LE, Trout TJ (2005) Relationships among vine- and soilbased measures of water status in a Thompson Seedless vineyard in response to high-frequency drip irrigation. Am J Enol Vitic 56(4):357-366

Yuste J, Gutiérrez I, Rubio JA, Alburquerque MV (2004) Leaf and stem water potential as vine water status indicators in Tempranillo grapevine under different water regimes in the Duero Valley. J Int Des Sci (De la Vigne et du Vin) 38:21-26

Zufferey VJ (2000) Echanges gazeux des feuilles chez Vitis vinifera L. (cv. Chasselas) em fonction des parametres climatiques et physiologique et des modes de conduitte de la vigne. Dissertation, Ecole Polytechnique Federale de Zurich, p 335 